\title{
O Uso da Cinesioterapia no Pré e Pós-operatório das Cirurgias na Artic ulação Temporomandibular
}

Henrique Ayres de Vasconcellos*

Antônio Eduardo de Siqueira Campos**

\section{RESUMO}

As condições funcionais da articulação temporomandibular (ATM) dependem do seu equilíbrio biomecânico com as estruturas do sistema estomatognático (oclusão dentária, músculos da mastigação) e demais peças músculo-articulares do crânio e da coluna cervical. No atendimento pré e pós-operatório do paciente que sofre cirurgia da ATM, a redução dos desvios funcionais de braço de alavanca, da hipotonia muscular, da contratura dos músculos da cabeça, pescoço e da mastigação facilitam as correções e melhoram a recuperação funcional da ATM com a utilização da cinesioterapia. Temos observado resultados eficientes na recuperação da dinâmica normal e redução do tempo e das seqüelas funcionais ao nível da ATM.

\section{UNITERMOS}

Articulação temporomandibular. Disfunção craniomandibular. Cirurgia na ATM. Cinesioterapia.

\section{SUMARY}

The physiological conditions of temporomandibular joint (TMJ) depend upon its biomechanical relation with the stomatognathic system (dental occlusion, mastigation muscles) and musculotendinou craniocervical portions. Preoperative and postoperative management of surgical patients can reduce problems of tension in the craniocervical and masticatory muscles and also facilitates the rehabilitation of TMJ. Use of kinesiotherapy may lead to dynamic recuparation of TMJ as well as to a reduction of functional sequels and a time saving treatment of TMJ.

\section{KEY WORDS}

Temporomandibular joint. Craniomandibular dysfunction. TMJ surgery. Kinesiotherapy.

\section{Introdução}

As observações da anátomo-fisiologia da ATM têm mostrado um grau intenso de dificuldade quanto aos aspectos do equilíbrio funcional desta articulação (Vasconcellos, 1982, 1991, 1993).

As variações da posição dentária, o espasmo muscular, a dor podem limitar a abertura da boca com ou sem desvios da mandíbula (Dufourmentel, 1929; Zlotnik, 1972; Schwartz, 1973; Genovese \& Tortamano, 1975).

A cirurgia bucomaxilofacial necessita da preparação prévia do paciente cirúrgico e de sua pronta recuperação quando da correção de disfunção da ATM, seja devido a lesões congênitas ou mesmo de

\footnotetext{
Professor Doutor. Serviço de Fisiatria-Hospital dos Servidores do Estado (MS-RJ), Dept. Anatomia/IB/UERJ.

** Mestre. Hospital do IASERJ (RJ); Dept. Anatomia/ IB/ UERJ.

Endereço para correspondência:

Caixa Postal $n^{\circ} 46523$ - CEP 20552-970 - Rio de Janeiro - RJ.
} 
traumas diretos ou indiretos sobre as estruturas que compõem o sistema estomatognático. Muitas vezes, o alongamento muscular e o fortalecimento das condições funcionais dos músculos da mastigação são a meta a ser alcançada nestes tratamentos.

O objetivo deste trabalho é comentar a indicação e o uso da cinesioterapia na recuperação funcional da ATM, seja no pré ou no pósoperatório das cirurgias sobre a articulação temporomandibular.

\section{Anatomia da ATM}

Trata-se de uma articulação sinovial bicondilar, cujas superfícies articulares são a eminência articular, a fossa mandibular do osso temporal e a cabeça da mandíbula (côndilo). Estas superfícies estão cobertas por uma cartilagem fibrosa, existindo um disco articular entre elas. A cápsula articular é um invólucro de tecido conjuntivo denso contendo líquido sinovial. Há uma divisão da cavidade em dois compartimentos: o supradiscal, com capacidade para 1,3 a 2,0 ml, e o infradiscal, com 0,5 a 1,0 ml. São descritos ligamentos justa-articulares e extraarticulares. Os músculos masseter, temporal, pterigóideos lateral e medial, e os das regiões supra e infra-hioídeas mobilizam a ATM (Vasconcellos, 1989, 1991; Madeira, 1995).

\section{Pacientes}

Os pacientes atendidos pelo serviço de fisiatria do HSE-RJ, oriundos de serviços de cirurgia bucomaxilofacial, são, na sua maioria, casos de seqüelas pós-traumáticas sobre a articulação (fraturas de mandíbula) e casos de cirurgia para a correção de anquiloses congênitas da ATM. Estes pacientes apresentam limitações, geralmente dolorosas, da amplitude de movimentos da boca, dificuldades para alimentação (abertura de boca e deglutição) e por vezes até mesmo problemas para a fonação.

Quando o paciente é encaminhado no préoperatório, após a avaliação de contraturas musculares, dores à apalpação destes músculos e / ou da própria ATM (intra ou extra-auricular), é iniciado o tratamento específico de alongamento e, se possível, o fortalecimento muscular através de exercícios ativos da boca com e sem resistência (Hansson et al., 1988; Vasconcellos, 1991) (fig. 1).

No pós-operatório recebemos pacientes apresentando a correção de seu problema mas ainda com limitação funcional, dolorosa ou não, e que necessitam voltar ao seu estado anterior. São adultos ou crianças que operaram uma fratura de ramo ou corpo mandibulares, ou ainda crianças passando por mais um estágio na cura cirúrgica de anquiloses da ATM. Nestes casos podemos nos deparar com mais um problema, que é a paralisia facial periférica do lado operado, ocasionada por uma neuropraxia causada pelo manuseio cirúrgico. O tratamento é conduzido para os dois problemas, sendo que geralmente as crianças, apesar de cirurgias extensas, têm uma recuperação mais rápida com os exercícios ativos para a estimulação dos músculos da expressão facial. Tanto nos pacientes adultos como nas crianças, empregamos também a massagem (deslizamento superficial) complementando a terapia recuperacional.

A indicação da cinesioterapia dependerá da avaliação do caso e da liberação pela cirurgia bucomaxilofacial quanto à mobilização dos segmentos envolvidos. Alguns casos necessitam da termoterapia e/ou da crioterapia, por 20 minutos, com algumas repetições diárias, para uma analgesia local, prévia ao tratamento cinesioterápico.

\section{Discussão}

Madeira (1995) enfatiza a importância do trabalho muscular quando dos movimentos da boca. Refere que músculos como o pterigóideo lateral, ativo na protrusão (propulsão), e o 
digástrico (retrusor) são importantes nestes movimentos, que por isso mesmo devem ser mantidos em constante equilíbrio. A mastigação e a ATM sendo adaptadas à mastigação molar, a simples mudança para uma mastigação do tipo incisiva pode transferir uma carga 2 vezes maior para a articulação.

Os meios diagnósticos atuais nos permitem observar deslocamentos, redutíveis ou não, do disco da ATM, possibilitando, também, a observação de contraturas de músculos de difícil exame físico. Estes fatos permitem que possamos intervir sobre estes pacientes, com o tratamento cinesioterápico recuperacional, necessário após artrocenteses, cirurgias ou artroscopias da ATM (Schellhas, 1989; Vasconcellos, 1991).

Nos pacientes encaminhados ao nosso serviço procuramos acompanhar a progressiva evolução recuperacional do caso, enviando o paciente a avaliação odontológica quando percebemos queixas de distúrbios oclusionais pós-cirúrgicas.

\section{Conclusão}

Acreditamos que a eficiência da indicação, da aplicação e do acompanhamento do fisiatra no tratamento cinesioterápico do paciente pré e pósoperado, devido a uma disfunção craniomandibular, deva ser vista de maneira muito intensa procurando uma integração com as clínicas odontológicas e bucomaxilofaciais, para um bom resultado final do tratamento.

\section{Referências Bibliográficas}

1. DUFOURMENTEL, L - Chirurgie de l'articulation temporo maxilaire. Paris, Masson, 1929.

2. GENOVESE, J.W.; Torta ma no, N. - Disfunções da a rtic ula ção temporomandibular. Rev. Assoc. Paul. Cir. Dent. 29:31-40, 1975.

3. HANSSO N, T; HESSE, J ; HONNÉ, W.; J IMÉNEZ, V. - Disfunción cráneo-mandibular. Barcelona, Praxis, 1988.

4. MADEIRA, M.C. - Anatomia da face: Bases anatomofuncionais para a prática odontológica. São Paulo, Sa vier, 1955.

5. SCHELLHAS, K.P. - MR Imaging of musc les of mastication. AJ NR 10:829-837, 1989.

6. SCHWARTZ, L.; CHAYES, C.M. - Dolor facial y disfunción mandibular. Buenos Aires, Múndi, 1973.

7. VASCONCELLOS, H.A. - Considerações sobre o uso de procedimentos cinesioterá picos na disfunção da a rtic ula ção temporoma ndibular. O.M. 9(6):21-25, 1982.

8. - Músculos da mastigação e da coluna cervical: estudo a natomofuncional a plic ado. O.M. 16(4):13-17, 1989.

9. _ - Disfunção temporomandibula r: a spectos a nato mossemiológic os. Rev. Med. Reabil. 28:7-8, 1991.

10. ___ SILVA, D.S.; BARBOSA, S.A. - O disco da a rticulação temporomandibula r: revisã o a na to mofunc ional a plic a da R.B.O. 50(3):32-36, 1993.

11. ZLOTNIK, J. - Articulação temporomandibular: considerações acerca da disfunção. ARS Curandi 5:5862,1972 